\title{
Live attenuated African swine fever viruses as ideal tools to dissect the mechanisms involved in viral pathogenesis and immune protection
}

\author{
Anna Lacasta 1,2, Paula L. Monteagudo 1, Ángeles Jiménez-Marín³, Francesc Accensi ${ }^{1,4}$, María Ballester 1,5, \\ Jordi Argilaguet ${ }^{6}$, Iván Galindo-Cardiel ${ }^{1,7}$, Joaquim Segalés ${ }^{1,4}$, María L. Salas ${ }^{8}$, Javier Domínguez ${ }^{9}$, \\ Ángela Moreno ${ }^{3,10}$, Juan J. Garrido ${ }^{3}$ and Fernando Rodríguez ${ }^{1 *}$
}

\begin{abstract}
African swine fever virus (ASFV) is the causal agent of African swine fever, a hemorrhagic and often lethal porcine disease causing enormous economical losses in affected countries. Endemic for decades in most of the sub-Saharan countries and Sardinia, the risk of ASFV-endemicity in Europe has increased since its last introduction into Europe in 2007. Live attenuated viruses have been demonstrated to induce very efficient protective immune responses, albeit most of the time protection was circumscribed to homologous ASFV challenges. However, their use in the field is still far from a reality, mainly due to safety concerns. In this study we compared the course of the in vivo infection caused by two homologous ASFV strains: the virulent E75 and the cell cultured adapted strain E75CV1, obtained from adapting E75 to grow in the CV1 cell-line. Interestingly, the kinetics of both viruses not only differed on the clinical signs that they caused and in the virus loads found, but also in the immunological pathways activated throughout the infections. Furthermore, E75CV1 confirmed its protective potential against the homologous E75 virus challenge and allowed the demonstration of poor cross-protection against BA71, thus defining it as heterologous. The in vitro specificity of the $C D 8^{+}$T-cells present at the time of lethal challenge showed a clear activation against the homologous virus (E75) but not against BA71. These findings will be of utility for a better understanding of ASFV pathogenesis and for the rational designing of safe and efficient vaccines against this virus.
\end{abstract}

\section{Introduction}

African swine fever (ASF) is a highly pathogenic disease caused by African Swine Fever Virus (ASFV), a rather complex virus against which there is no vaccine available. Thus, eradication of the disease has relied, so far, on early diagnosis and subsequent culling of infected and exposed pigs. Only 10 years after its eradication from continental Europe, ASFV re-entered Europe arriving from Africa to the Caucasian Republic of Georgia in 2007. Since then,

\footnotetext{
*Correspondence: fernando.rodriguez@irta.cat

${ }^{1}$ Centre de Recerca En Sanitat Animal (CReSA), Institut de Recerca i Tecnologia Agroalimentàries (IRTA), Campus UAB, Bellaterra, 08193 Barcelona, Spain

Full list of author information is available at the end of the article
}

ASFV has spread to neighboring countries including Russia, already reaching some E.U. countries and due to the global commercialization exchanges existing today, also menacing the rest of the world [1]. The risk of endemicity in Eastern European countries has dramatically increased in recent years due to the lack of enough preparedness and resources to implement successful control programs in the affected regions with both domestic pigs and wild boars being equally affected [2]. The risk of new introductions or reintroductions of the virus in ASF-free areas is high, overall taking into account the complex epidemiological situation of ASFV in Africa [3], with more than 22 genotypes currently circulating in the area [4] and the ease with which the virus can spread $[5,6]$. With these antecedents at hand, having a safe and efficient 
vaccine might increase the chances of controlling ASF in the future. Work done decades ago, demonstrated the failure of classically inactivated vaccine in achieving strong protection against experimental ASF infection [710]. Conversely, classically attenuated vaccines have been shown to be very efficient at controlling homologous experimental challenges, albeit in a rather limited way against heterologous virus challenges $[11,12]$. In spite of their success, the use of live attenuated vaccines (LAV) in the field has been limited mainly due to safety problems derived from their inherent infectious nature [13]. More recently, new generation vaccines have created expectations for the future. The identification of key protective antigens within the ASFV genome [14] has allowed the possibility of attempting the design of safe DIVA vaccines for the future [15]. On the other hand, recombinant deletion of targeted virulence factors should theoretically permit the generation of efficient modified LAV against ASFV [16-18] with increased security; a field in continuous progression. Independent of their safety problems, to date LAV have provided the most relevant data regarding the mechanisms involved in ASFV-protection. Thus, today we know that both specific antibodies [19] and specific CD8 ${ }^{+}$T-cells [20] play crucial role in the protection afforded by LAV. Despite this, the mechanisms involved in the protection afforded by antibodies are still largely unknown and several mechanisms have been proposed [21]. Similarly, $\mathrm{CD} 8^{+} \mathrm{T}$-cells have been postulated as a key $\mathrm{T}$ cell subset in the protection afforded by both LAV [20] and DNA vaccines [14, 15]. More advanced genomic and proteomic methodologies have opened new alternatives to better understand not only the intrinsic mechanisms involved in protection but also the early and late events implicated in viral pathogenesis. Few studies have been published so far using microarrays and almost all of them have focused on comparing the effects of ASFV strains with different virulence in vitro [22]. Albeit useful in general terms, further work is needed using well characterized homologous ASFV strains to specifically identify individual virulence factors. As above described, previous results obtained in the 80s with the attenuated E75CV1 strain [11], demonstrated the fine balance existing between death and survival after intranasal experimental infection and the capability of surviving animals to resist subsequent lethal challenge with the homologous virulent E75 virus. Here we have extended the use of the virulent E75 and its cell culture adapted counterpart E75CV1 to better compare the in vivo immunopathogenesis of both viral strains and also to understand the intrinsic mechanisms involved in protection afforded against the homologous lethal challenge. To perform these studies the optimal dose for intramuscular inoculation of E75CV1 was first standardized and next an experimental set up was designed to compare: (1) the kinetics of the E75 and E75CV1 viral infection, (2) the evolution of induced innate and specific immune responses and (3) the protective potential of E75CV1 against homologous and heterologous challenges. The sequential sampling of sera, nasal swabs, and lymphoid tissues together with a multi-technical approach allowed the further characterization of both ASFV pathogenesis and protection and has opened new avenues for further research.

\section{Materials and methods}

\section{Virus strains and ethical statements}

Three different ASFV strains were used in the in vivo and in vitro experiments: BA71, E75 and E75CV1. BA71 and E75 strains (both virulent) were isolated from the 1971 and 1975 Spanish ASF outbreaks, respectively. Afterwards, they were further propagated in pig leucocytes. E75CV1 isolation was achieved by 4 consecutive passages in CV1 cells (green monkey kidney fibroblasts) [11].

Experiments with 8-week-old Landrace X Large White pigs (conventional farm pigs) were performed under the approval of the Ethical and Animal Welfare Committee of the Universitat Autònoma de Barcelona (UAB; Permit Number: DMAH-5796) and infections with ASFV were done under biosecurity level 3 (BSL-3) conditions at Centre de Recerca en Sanitat Animal (CReSA, Barcelona, Spain).

\section{Experimental design for the in vivo experiments}

Pigs were intramuscularly inoculated (i.m.i.) in the neck with $1 \mathrm{~mL}$ of the corresponding ASFV dose and virus strain diluted in PBS $1 \mathrm{X}$ pH 7.4 or with PBS $1 \mathrm{X} \mathrm{pH} \mathrm{7.4}$ alone as control of the assay. Animals were observed daily according to a welfare schedule to monitor their health status and to record the clinical signs after the infection with ASFV [23].

\section{Experiment 1: selecting the optimal dose for E75CV1-immunization}

Sixteen pigs were divided into 4 groups with 4 pigs in each one and received either PBS $1 \mathrm{X}$ pH 7.4 (control animals) or three different doses of the cell culture adapted strain E75CV1: $10^{2} 50 \%$ hemadsorbing units $\left(\mathrm{HAU}_{50}\right)$, $10^{4} \mathrm{HAU}_{50}$ and $10^{5} \mathrm{HAU}_{50}$.

\section{Experiment 2: comparative kinetics of E75 and E75CV1 infections}

Fifty four pigs were divided into three groups that were maintained in isolation from each other: (a) 24 pigs were infected with the optimal dose of the attenuated E75CV1 ASFV strain, obtained from the experiment $1: 10^{4} \mathrm{HAU}_{50}$ and sequential blood sampling and necropsies were performed in groups of 6 pigs at days: $1,3,7$ 
and 31 post-infection (pi); (b) 18 pigs were infected with the same dose $\left(10^{4} \mathrm{HAU}_{50}\right)$ of E75, the homologous virulent virus and again groups of 6 pigs were sequentially sampled, sacrificed and subjected to necropsy at days 1 , 3 and 7 pi; (c) finally, 12 animals remained uninfected and were sequentially sampled and sacrificed in groups of 3 at days 1, 3, 7 and 31 pi as controls. All animals were sampled prior to the infection (day $0 \mathrm{pi}$ ). During necropsies all animals and organs of interest (spleen, gastrohepatic lymph node, liver and kidneys) were weighted separately in order to establish their relative weight: percentage of the total body weight that the specific organ represents.

\section{Experiment 3: homologous versus heterologous ASFV-challenge}

Sixteen pigs were divided in two groups housed separately, from this point on termed BOX-1 and BOX-2 respectively. Four pigs from each room were i.m.i. inoculated with $10^{4} \mathrm{HUA}_{50}$ of the E75CV1 (optimal dose of immunization selected in experiment 1 ), and the other four from each box remained uninfected receiving the same volume of PBS $1 \mathrm{X} \mathrm{pH} \mathrm{7.4.} \mathrm{Twenty-eight} \mathrm{days} \mathrm{after}$ E75CV1-inoculation all pigs from BOX-1 were challenged with $10^{4} \mathrm{HAU}_{50}$ of the homologous E75 strain, and pigs from BOX-2 were challenged with $10^{3} \mathrm{HAU}_{50}$ of BA71; corresponding to 20 lethal dose fifty $\left(\mathrm{LD}_{50}\right)$ for each one of the ASFV strains ([24] and unpublished data).

\section{Virus titration}

Blood samples were collected before and at different times after virus challenge for viremia quantification using the haemadsorption technique, as previously described $[14,25]$. Titres were calculated by the Reed and Muench method [26] and expressed as $\mathrm{HAU}_{50} / \mathrm{mL}$.

A real time quantitative PCR (qPCR) method recently described in our laboratory [15], was used to quantify the viral DNA from nasal swabs-PBS suspensions and tissues (gastrohepatic lymph node). Briefly, the viral DNA was obtained from $200 \mu \mathrm{L}$ of swab-PBS suspensions using the NucleoSpin blood kit or from $25 \mathrm{mg}$ of tissue using NucleoSpin tissue kit (both from Macherey-Nagel, Düren, Germany) following the manufacturer's recommendations and used as template to amplify an $85 \mathrm{bp}-$ long fragment from the ASFV serine protein kinase gene (R298L). PCR amplifications were performed in triplicate using the corresponding standards for absolute quantification. The results were expressed as $\log _{10}$ genome equivalent copies (GEC) per $\mathrm{mL}$ of nasal swab.

Additionally ASFV-infected macrophages were doublestained using the antibodies anti-CD172a (hybridoma clone BA1C11), specific for monocytes and macrophages and anti-p30 (hybridoma clone 1D9), specific for the p30 virus structural protein, and after secondary staining, the cells were FACS-analyzed [15].

\section{Histopathology and microscopic tissue evaluation}

Tissue samples (spleen, gastrohepatic lymph node, liver and kidneys) were previously fixed in $10 \%$ formalin (Sigma-Aldrich, Madrid, Spain) and embedded in paraffin-wax for histological processing. Four $\mu \mathrm{m}$-sections were stained with haematoxylin and eosin for microscopical examination. Infiltration of macrophages, apoptosis and ASFV-antigen detection were evaluated by specific immunohistochemical methods as briefly described below. Tissue sections were incubated for $30 \mathrm{~min}$ in a $3 \%$ hydrogen peroxide solution (diluted in absolute methanol) to inhibit the endogenous peroxidase. Afterwards, the sections were treated with EDTA $(0.37 \mathrm{mg} / \mathrm{mL}$, diluted in PBS 0.5\% Tween20, $\mathrm{pH} 8$ ) at $98{ }^{\circ} \mathrm{C}$ for $15 \mathrm{~min}$ and then blocked with $2 \%$ bovine serum albumin (BSA, Sigma-Aldrich, Madrid, Spain) for $1 \mathrm{~h}$ at room temperature for further specific antibody labeling. Both, primary and secondary antibodies were incubated for $18 \mathrm{~h}$ at $4{ }^{\circ} \mathrm{C}$ and subsequently treated with the avidin-biotin complex solution (ABC, Thermo Scientific, Rockford, IL, USA); labeling was revealed with 3,3'-diaminobenzidine (DAB, Sigma-Aldrich, Madrid, Spain).

Infiltrated macrophages were detected using the antiMAC387 rabbit-antibody (1:40, Dako, Barcelona, Spain) and apoptotic cells were detected using an anti-caspase-3 rabbit-antibody (1:100, Cell Signaling Technology, Barcelona, Spain). In both cases the secondary antibody used was an anti-rabbit IgG peroxidase conjugated (1:100, Dako, Barcelona, Spain). ASFV-infected cells were detected using an anti-p30 antibody (undiluted clone 1D9) generously provided by INIA (Madrid) and using as a secondary antibody an anti-mouse IgG peroxidaseconjugated antibody (1:200, Dako, Barcelona, Spain).

\section{Measuring specific antibody responses}

ASFV specific antibodies in pig sera were detected by the OIE-approved ELISA assay based on the use of soluble extracts from ASFV infected cells [27]. The presence of positive sera was detected using $100 \mu \mathrm{L}$ of peroxidaseconjugated anti-pig IgG at 1/20 000 dilution (SigmaAldrich, Madrid, Spain) as secondary antibody and 50 $\mu \mathrm{L}$ of soluble $3,3^{\prime}, 5,5^{\prime}$-tetramethylbenzidine (TMB) as specific peroxidase substrate (Sigma-Aldrich, Madrid, Spain). Reactions were stopped with $50 \mu \mathrm{L}$ of $1 \mathrm{~N} \mathrm{H}_{2} \mathrm{SO}_{4}$ (Sigma-Aldrich, Madrid, Spain) per well. The plates were read at $450 \mathrm{~nm}$ wavelength $\left(\lambda_{450}\right)$ and the results were represented as the average absorbance (optical density (OD) values) between duplicates. Additionally, sera were used to test their ability to inhibit the in vitro infection 
of E75 in porcine alveolar macrophages following slightly modified previously described protocols [28]. Briefly, serial dilutions of sera (1:10 and 1:20) were first complement-inactivated at $56{ }^{\circ} \mathrm{C}$ for $30 \mathrm{~min}$. After inactivation the sera dilutions were incubated with $4 \times 10^{5} \mathrm{HAU}$ of E75 for $1 \mathrm{~h}$ at $37^{\circ} \mathrm{C}$ (gently mixed every $15 \mathrm{~min}$ ), prior to the infection of porcine alveolar macrophage monolayers $\left(4 \times 10^{5}\right.$ cells/well in a 96-well plate) for $72 \mathrm{~h}$. The ASFV titres were finally expressed as $\mathrm{HAU}_{50} / \mathrm{mL}$ by using the haemadsorption technique [31].

\section{Measuring specific T-cell responses}

Peripheral blood mononuclear cells (PBMCs) were isolated from whole blood by density-gradient centrifugation with Histopaque 1077 (Sigma-Aldrich, Madrid, Spain). For PBMC cultures, RPMI 1640 medium supplemented with $10 \%$ fetal calf serum (Invitrogen, Barcelona, Spain), 50000 IU penicillin/l (Invitrogen, Barcelona, Spain) and $50 \mathrm{mg}$ streptomycin/l (Invitrogen, Barcelona, Spain) was used. Trypan blue was used to assess cellviability. The frequency of ASFV-specific IFN $\gamma$-secreting cells (IFNy-SC) in PBMC was analyzed by an ELISPOT assay using commercial mAbs (Swine IFN $\gamma$, Cytoset; Biosource Europe) following a previously reported method [15]. PBMCs were specifically stimulated in vitro with $10^{6}$ $\mathrm{HAU}_{50} / \mathrm{mL}$ of the E75 ASFV strain for $20 \mathrm{~h}$ and $10 \mu \mathrm{g} /$ $\mathrm{mL}$ Phytohemaglutinin (PHA, Sigma-Aldrich, Madrid, Spain) was used as positive control for the assay. To calculate the frequencies ASFV-specific IFN $\gamma$-SC, counts of spots in unstimulated wells were subtracted from counts in virus-stimulated wells. The frequency of cytokineproducing cells was expressed as responding cells in $10^{6}$ PBMCs.

Alternatively, PBMCs were labeled with carboxyfluorescein diacetate succinimidyl ester (CFSE, Vybrant CFDA SE Cell Tracer kit, Invitrogen, Barcelona, Spain), in vitro stimulated with $10^{6} \mathrm{HAU}_{50} / \mathrm{mL}$ of either the E75 or the BA71 ASFV strains for $72 \mathrm{~h}$, and finally cell viability was assessed by staining with LIVE/DEAD ${ }^{\circledR}$ Fixable Violet Dead Cell Strain Kit (Invitrogen, Barcelona, Spain) and surface-labeled with anti-CD8-AlexaFluor647 (clone 76-2-11) and anti-CD4-PerCPCy5.5 (clone 74-124) antibodies (BD Pharmingen, NJ, USA), allowing the phenotyping of the virus-specific proliferating cells [29]. Combining these two markers, three different T-cell populations could be defined [30]: CD4 ${ }^{+}$T-cells (single positive CD4), cytotoxic T-cells or CTLs (single positive $\mathrm{CD} 8^{\text {high }}$ ) and memory T-cells (double positive $\left.\mathrm{CD} 4^{+} \mathrm{CD} 8^{\text {low }}\right)$.

\section{Analysis of relative gene expression by qPCR}

After necropsy, gastrohepatic lymph node samples were aseptically collected, overnight treated with
RNAlater ${ }^{\circledR}$ (Ambion, Austin, TX, USA) at $4{ }^{\circ} \mathrm{C}$ to increase the RNA stability of the tissues and next frozen at $-80{ }^{\circ} \mathrm{C}$ for further RNA isolation. RNA was isolated using the RNeasy Mini kit (Qiagen, Valencia, CA, USA), treated with RNase-free DNase Set (Qiagen, Valencia, CA, USA) and impurities removed with RNeasy Minielute kit (Qiagen, Valencia, CA, USA), following the manufacturer's instructions. The integrity, quality and quantity of RNA obtained was checked in $1 \%(\mathrm{w} / \mathrm{v})$ agarose gels and using a NanoDrop ${ }^{\mathrm{TM}} 1000$ Spectrophotometer (Thermo Scientific, Rockford, IL, USA). qPCR technology was used to determine the relative expression of a panel of 19 swine gene transcripts representative of Th1, Th 2 and Th 17 responses (Table 1 ), previously described $[31,32]$. One $\mu$ g of RNA isolated from infected and control animals at different times post-infection was reverse transcribed to cDNA using the iScript cDNA Synthesis kit (BioRad, Hercules, CA, USA). Three animals from each time point and group were selected taking into account the quality and quantity of the RNA obtained. A PCR specific for the $18 \mathrm{~S}$ was performed with all $\mathrm{cDNAS}$ in order to assess their quality. Final concentration of primers in the PCR reactions was $0.5 \mu \mathrm{M}$ and primers (Table 1) were designed using Beacon Designer ${ }^{\mathrm{TM}}$ (Biosoft International, Palo Alto, CA, USA) and internal normalization of the gene expression analysis was carried out by using beta-actin and PPIA as reference genes [33]. The relative gene expression was assessed by the $2^{-\Delta \Delta \mathrm{Ct}}$ method [34] and applied as previously described [31]. With this method, a fold-change value of 1 or -1 represents no difference in gene expression. The differences in mRNA expression among groups were assessed by the Student's paired T-test using SigmaPlot v10.0 (Systat Software Inc., CA, USA). Values of $p<0.05$ were considered as being significant.

\section{ELISA detection of serum soluble factors}

Serum samples were harvested in polypropylene tubes and stored at $-80{ }^{\circ} \mathrm{C}$ until use. ELISA was used for serum interferon- $\alpha$ (IFN- $\alpha, \mathrm{R} \& \mathrm{D}$, Minneapolis, MN, USA) and tumour necrosis factor- $\alpha$ (TNF- $\alpha, R \& D$, Minneapolis, MN, USA), according to the manufacturer's instructions. Respective standard curves were used to determine the amounts $(\mathrm{U} / \mathrm{mL}$ in IFN- $\alpha$ assay and $\mathrm{pg} / \mathrm{mL}$ in TNF- $\alpha$ assay) of each cytokine in the porcine serum samples. IFN- $\alpha$ and TNF- $\alpha$ amounts were measured both in control and infected pigs at each sampling time. Soluble CD163 (sCD163) was quantified in sera by a previously described enzyme-linked immunosorbent assay (ELISA), using lysates from CD163-transfected $\mathrm{CHO}$ cells as a standard, and results were expressed as the equivalent number of CD163-transfected cells [35]. 
Table 1 List of genes and sequences of the primers used for qPCR analysis.

\begin{tabular}{|c|c|c|c|}
\hline Gene name & Forward primer $\left(5^{\prime} \rightarrow 3^{\prime}\right)$ & Reverse primer $\left(5^{\prime} \rightarrow 3^{\prime}\right)$ & Accession number \\
\hline$\beta$-actin & CAGGTCATCACCATCGGCAACG & GACAGCACCGTGTTGGCGTAGAGGT & U07786 \\
\hline PPIA & CCTGAACATACGGGTCCTG & AACTGGGAACCGTTTGTGTTG & AY266299 \\
\hline 185 & GACTCAACACGGGAAACCTCAC & GCTTATGACCCGCACTTACTGG & AY265350 \\
\hline TNFa & ССТСТTСТССТTССТССТG & CCTCGGCTTTGACATTGG & $\times 57321$ \\
\hline $\mathbb{L L}-1 \beta$ & GGCCGCCAAGATATAACTGA & GGACCTCTGGGTATGGCTTTC & NM_214055 \\
\hline $\operatorname{IL}-4$ & TTGCTGCCCCAGAGAAC & TGTCAAGTCCGCTCAGG & AY294020 \\
\hline $\operatorname{lL}-5$ & TGGTGGCAGAGACCTTGACA & CCATCGCCTATCAGCAGAGTT & NM_214205.1 \\
\hline $\operatorname{lL}-6$ & TGGCTACTGCCTTCCCTACC & CAGAGATTTTGCCGAGGATG & NM_214399 \\
\hline $\operatorname{lL}-8$ & TTCGATGCCAGTGCATAAATA & CTGTACAACCTTCTGCACCCA & AB057440 \\
\hline $\operatorname{lL}-10$ & CAGATGGGCGACTTGTTG & ACAGGGCAGAAATTGATGAC & L20001 \\
\hline IL-12p40 & GGAGTATAAGAAGTACAGAGTGG & GATGTCCCTGATGAAGAAGC & U08317 \\
\hline $\mathbb{L L}-13$ & AAGTGGCCCAGTTCGTAAAAGA & ACCCGTGGCGAAAAATCA & NM_213803.1 \\
\hline$I L-17 A$ & CTCTCGTGAAGGCGGGAAT & TCCTCAGTTTTTGGGCATCCT & NM_001005729 \\
\hline $\operatorname{lL}-18$ & AGGGACATCAAGCCGTGTTT & CGGTCTGAGGTGCATTATCTGA & EU118362.1 \\
\hline $\mathbb{1 L}-21$ & CTGCCTGATGGTCATCTTCTCA & AGGCGATCTTGTCCTTGGAA & NM_214415 \\
\hline $\operatorname{lL}-23$ & GCTTGCAAAGGATCCACCAA & GGCTCCCCTGTGAAAATGTC & NM_001130236.1 \\
\hline$I F N-\gamma$ & CAAAGCCATCAGTGAACTCATCA & TCTCTGGCCTTGGAACATAGTCT & X53085 \\
\hline TGF- $\beta R 1$ & TCAGGCTTACCATTGCTTGTTCAG & CTCGCCAAACCTCTCCAAATCG & NM_001038639 \\
\hline DEFB1 & ACCGCCTCCTCCTTGTATTC & GGTGCCGATCTGTTTCATCT & NM_213838 \\
\hline DEFB2 & CTGTCTGCCTCCTCTCTTCC & CAGGTCCCTTCAATCCTGTT & NM_214442 \\
\hline$N F-K B$ & CTCGCACAAGGAGACATGAA & ACTCAGCCGGAAGGCATTAT & DQ834921 \\
\hline CD163 & GCCTGTCTCATCGCATTCCT & GGATTTAGCATATCCGTTTCATCTG & NM_213976.1 \\
\hline
\end{tabular}

\section{Results}

E75CV1, an ideal experimental infection model but not a safe vaccine prototype

Due to the complexity of standardizing a dose for E75CV1 intranasal immunization, the intramuscular route for E75CV1 in vivo inoculation was tested (Experiment 1). Therefore, 3 groups of four pigs each were i.m.i. with either $10^{2} \mathrm{HAU}_{50}, 10^{4} \mathrm{HAU}_{50}$ or $10^{5} \mathrm{HAU}_{50}$ of the E75CV1 strain and deaths were recorded during the course of the infection. Interestingly enough, all pigs i.m.i. with $10^{4} \mathrm{HAU}_{50}$ of E75CV1 survived the infection, while 2 out of the 4 pigs (50\%) that received ten times more virus $\left(10^{5} \mathrm{HAU}_{50}\right.$ of E75CV1), died at days 14 and $25 \mathrm{pi}$, respectively (Figure 1) with clear clinical signs of acute ASF. Intriguingly, infection with $10^{2} \mathrm{HAU}_{50}$ E75CV1 (100 times lower than the intermediate dose), also resulted in an unexpected course of the disease, which resolved with the death of 2 out of the 4 pigs by days 27 and 28 pi (Figure 1). The 2 surviving pigs showed no detectable viremia and very short peaks of mild fever while fatal cases coincided with the first appearance of ASF clinical signs by day $17 \mathrm{pi}$, correlating with the detection of viremia and fever (Figure 2A). Conversely, pigs succumbing after the challenge with $10^{5} \mathrm{HAU}_{50}$ of E75CV1 showed viremia and fever that peaked as early as day 5 pi, 3 days before the surviving animals that also showed

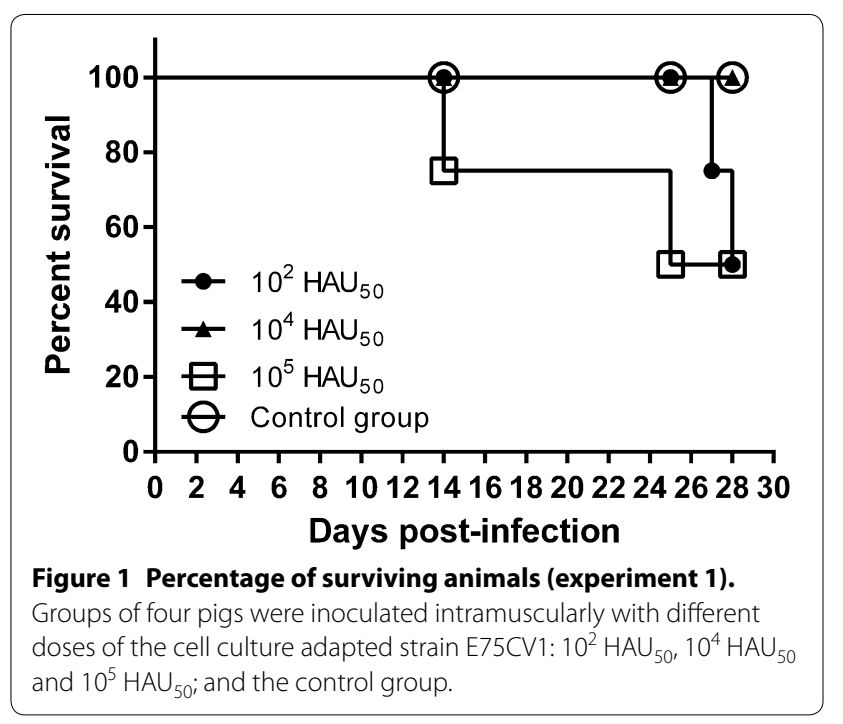

lower and shorter viremia and fever peaks (Figure 2B). Finally, i.m.i. with $10^{4}$ HAU of E75CV1 resulted optimal not only because there were no deaths (Figure 1) but also because pigs infected with this intermediate virus dose showed either no viremia and no clinical signs of acute ASF (in one of the pigs) or just limited viremia and fever episodes that reached undetectable levels by day $28 \mathrm{pi}$ 


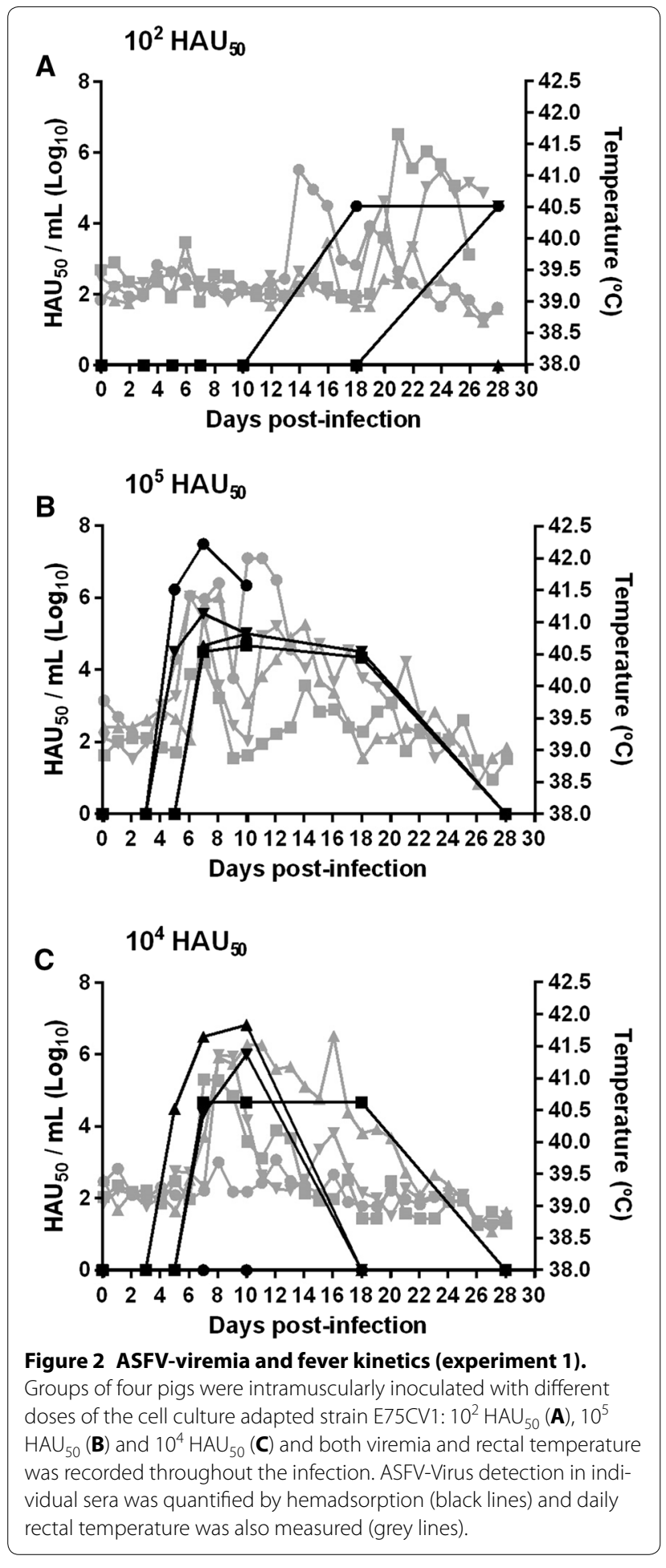

(Figure 2C), indicating a total recovery from ASFV infection. The detection of ASFV-specific antibodies from day 18 pi by ELISA (Figure 3A) and T-cells by IFNYELISPOT at day 28 pi (Figure 3C), clearly demonstrates
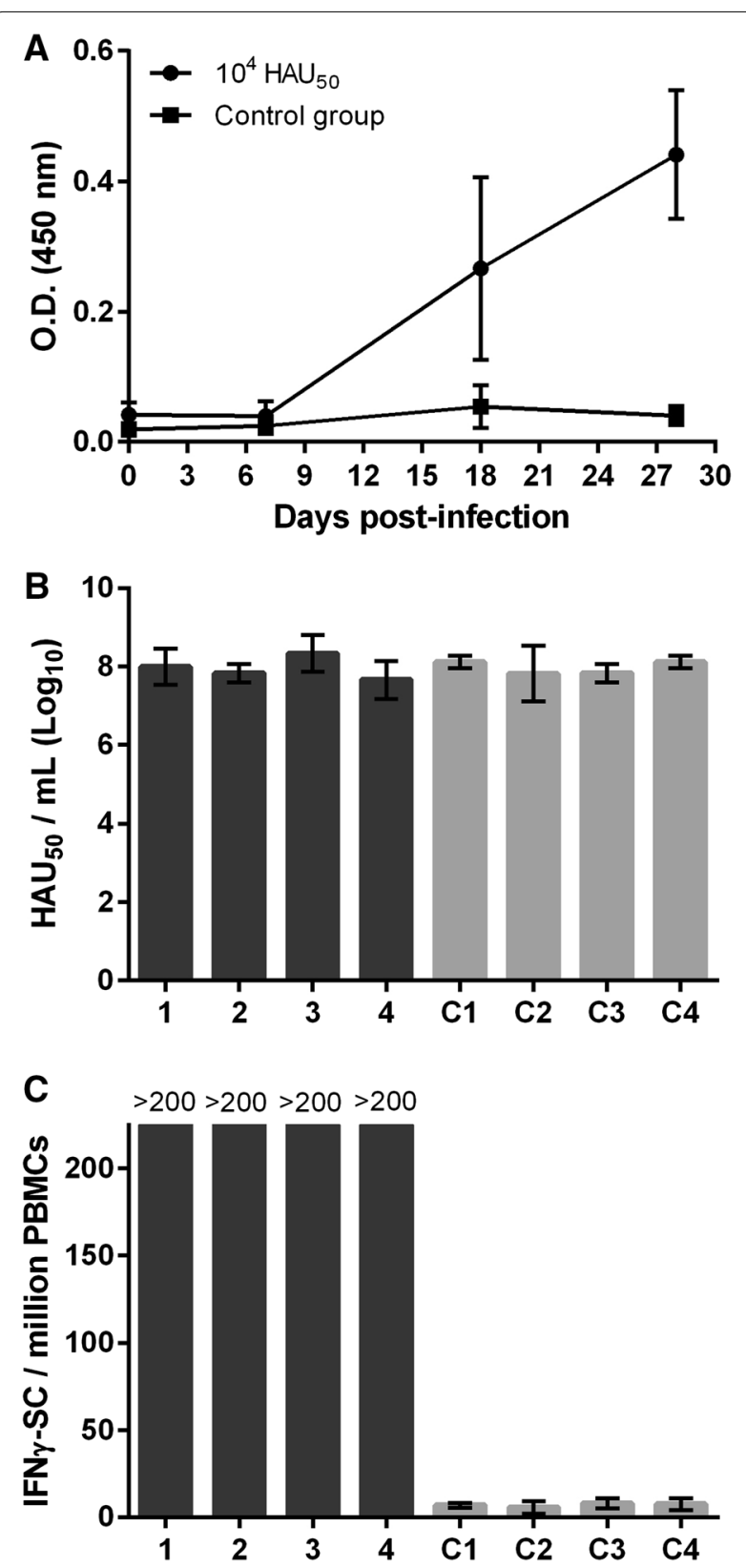

Figure 3 Specific immune responses induced by E75CV1

(experiment 1). Two groups of four pigs were intramuscularly inoculated with $10^{4} \mathrm{HAU}_{50} \mathrm{E} 75 \mathrm{CV} 1$ or were left as non-immunized controls. The kinetics of the individual specific antibody induction was monitored by ELISA. Average and standard deviation values are shown (A). At day 28 pi sera from the $10^{4} \mathrm{HAU}_{50}$ immunized animals were additionally subjected to an infection inhibition assay in vitro (B) and ASFV-specific T-cells were measured at day 28 pi by an IFNY-ELISPOT assay. Average values and standard deviation shown correspond to three individual experiments for the E75CV1-vaccinated (1-4) and control animals (C1-C4) (C)

the efficient infection of every single pig i.m.i. with $10^{4}$ HAU of E75CV1, including pig 1 that showed no viremia (Figure 2C), or ASF-compatible signs throughout the 
duration of the experiment (data not shown). In spite of the high titres of specific antibodies induced, sera from these animals were not capable to inhibit the ASFVinfection in alveolar macrophages (Figure 3B).

\section{E75CV1/E75, an ideal model for the characterization of ASFV immunopathogenesis}

In spite of its advantages, determining viral kinetics and the immunological responses induced throughout the infection by sequentially sampling (blood and nasal swabs) individual pigs, also have important limitations especially when considering full characterization of the in vivo pathogenesis of ASFV, a virus which mainly targets the lymphoid tissues. Therefore, a complex in vivo experiment was designed (Experiment 2) aiming to compare ASFV pathogenesis of cell culture adapted E75CV1 and its virulent homologous counterpart, E75. Taking advantage of the optimization of the intramuscular route for E75CV1 in vivo inoculation (Experiment 1), a group of 24 pigs was i.m.i. with $10^{4} \mathrm{HAU}_{50}$ of E75CV1, a second group of 18 pigs was infected using the same dose and route of the virulent E75 and finally a third group of 12 pigs remained uninfected (control group). Pigs from the three groups were sacrificed at days 1,3 and $7 \mathrm{pi}$ ( 6 or 3 per group and day) and 6 pigs from the attenuated E75CV1 and 3 from the control group were also sacrificed at day $31 \mathrm{pi}$. As expected for the virus and dose used [23], pigs infected with E75 developed severe ASF clinical signs, evident from day 3-5 pi, including: fever (Figure 4A), dyspnoea and depression. In contrast, the animals infected with the attenuated isolate (E75CV1) only developed, if at all, slight transient fever (Figure 4A). The viremia (Figure 4B), the viral excretion (Figure $4 \mathrm{C}$ ) and the infected macrophages counts in blood (Figure 4D) evolved in correlation with these observations. The animals infected with the attenuated
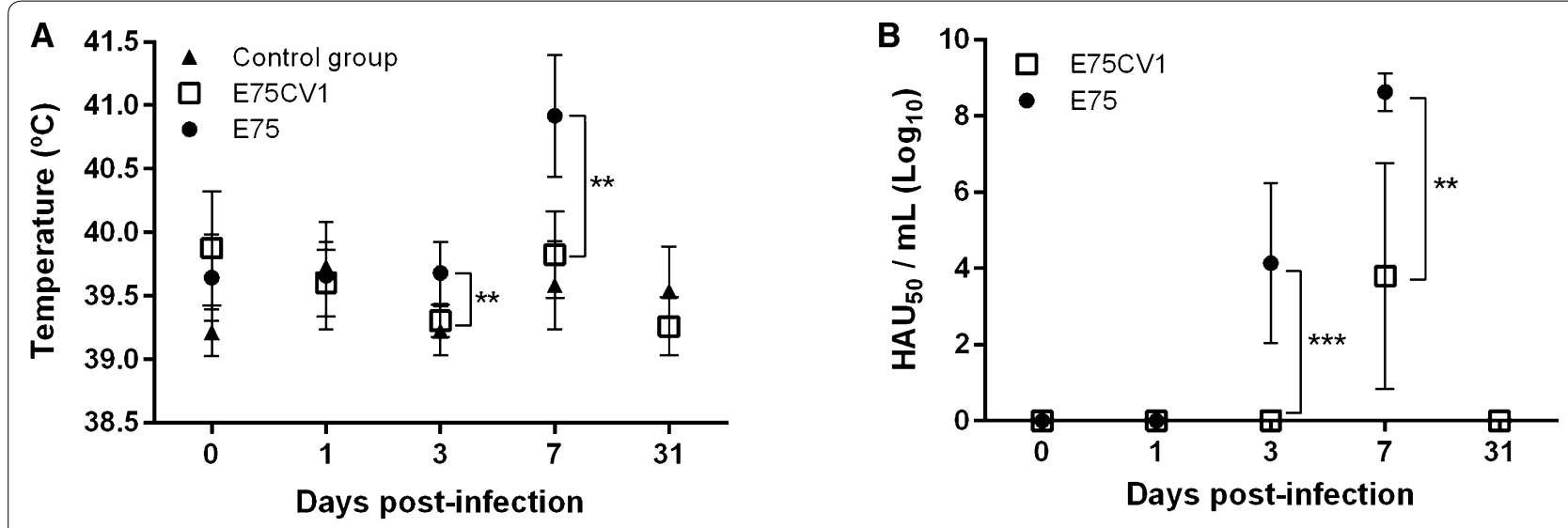

C
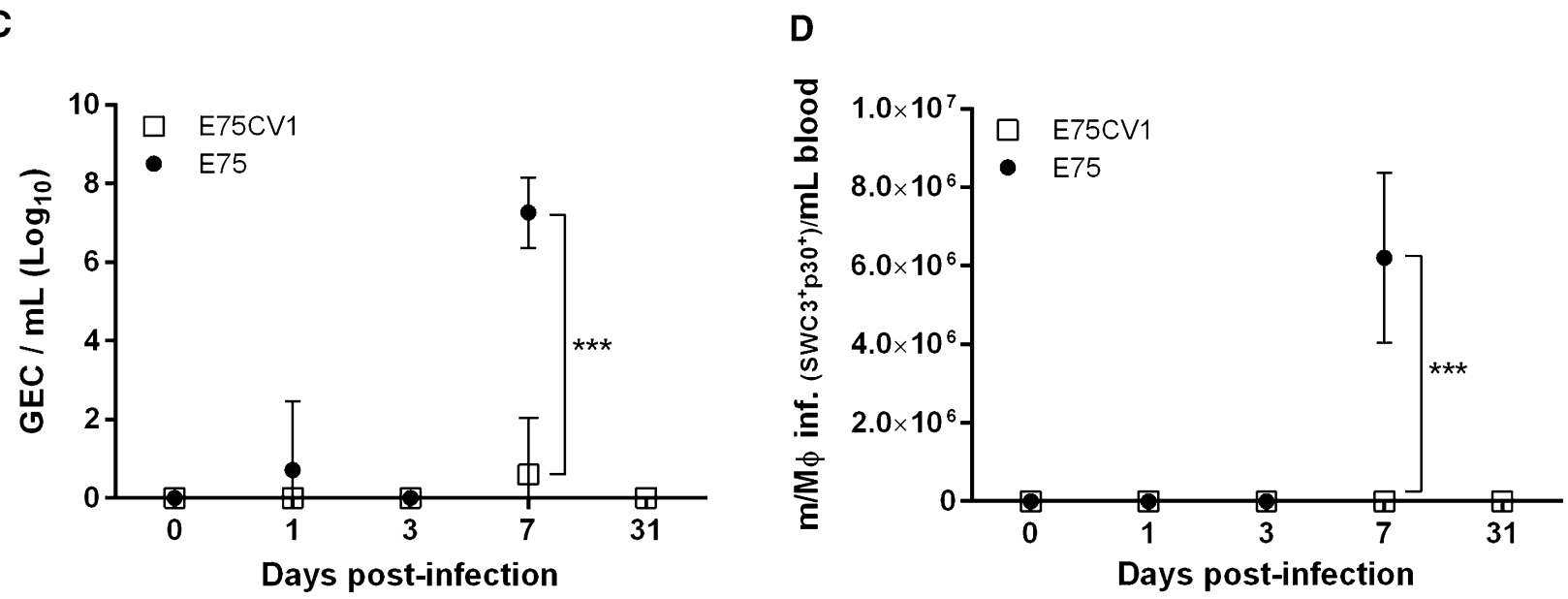

Figure 4 Comparative in vivo infection with virulent (E75) and attenuated (E75CV1) homologous ASFV-strains (experiment 2). ASFV infection was monitored over time by means of rectal temperature $(\mathbf{A})$, viremia as measured by haemadsorption (B), nasal viral excretion by means of qPCR $(\mathbf{C})$ and number of infected monocytes found in blood by cytometry (D) The graphs show average values and standard deviations per sixanimal group $\left({ }^{* *} p<0.01\right.$ and $\left.{ }^{* *} p<0.001\right)$. 
isolate suffered a delay in the virus detection in sera (Figure 4B), in nasal excretion (Figure 4C) and in the infected macrophages counts in blood (Figure 4D), detectable only at day 7 pi and the virus titres were $4-5$ logs lower on average than those found in pigs infected with the E75 virulent strain, reaching up to $10^{9} \mathrm{HAU}_{50} /$ $\mathrm{mL}$ in sera. The lesions found after necropsy, mostly in E75-infected pigs and taking into account the macro and micro organ structure, relative organ weight (Figure 5A), virus titres found (Figure 5B), the presence of cellular infiltrations, apoptosis and viral presence (Table 2), confirmed gastrohepatic lymph node as the organ of choice to further compare the immunopathogenesis of both virus strains. Total RNA isolation from gastrohepatic lymph nodes obtained from each animal and day of study allowed the establishment of a comparative transcription profile of key immune mediators that were differentially

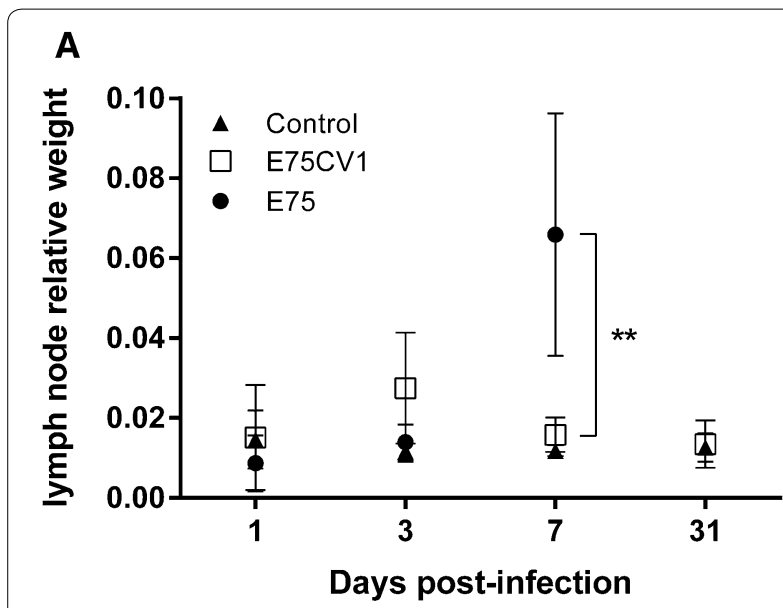

B

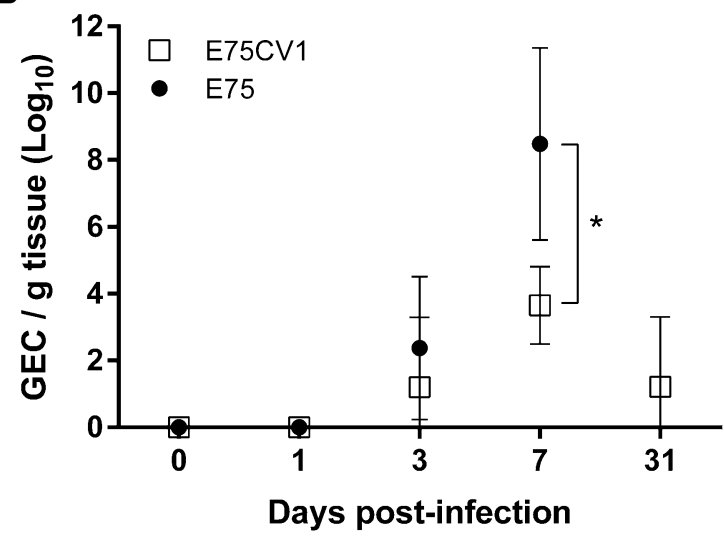

Figure 5 Gastrohepatic lymph nodes and ASFV-infection (experiment 2). Relative gastrohepatic lymph node weight versus total body weight $(\mathbf{A})$ and ASFV-titers found in gastrohepatic lymph node by means of $\mathrm{qPCR}(\mathbf{B})$. The figures show the average and the standard deviation of each six animal group $\left(^{*} p<0.05\right.$ and $\left.{ }^{* *} p<0.01\right)$.
Table 2 Histopathology evaluation (experiment 2). Quantification of macrophage infiltrations (A), presence of apoptotic cells (B) and ASFV antigen detection (C) in gastrohepatic lymph node.

\begin{tabular}{|c|c|c|c|c|c|}
\hline & Animal & Day 1 pi & Day 3 pi & Day 7 pi & Day 31 pi \\
\hline \multicolumn{6}{|l|}{ (A) } \\
\hline \multicolumn{6}{|c|}{ Macrophage infiltration $\left(\mathrm{MAC} 387^{+}\right)$} \\
\hline \multirow[t]{3}{*}{ E75 } & 1 & + & + & +++ & \\
\hline & 2 & + & + & +++ & \\
\hline & 3 & + & + & ++ & \\
\hline \multirow[t]{3}{*}{ E75CV1 } & 1 & + & + & + & + \\
\hline & 2 & ++ & ++ & ++ & + \\
\hline & 3 & ++ & + & ++ & + \\
\hline \multirow[t]{3}{*}{ Control } & 1 & + & + & + & + \\
\hline & 2 & + & + & + & + \\
\hline & 3 & + & + & + & + \\
\hline \multicolumn{6}{|l|}{ (B) } \\
\hline \multicolumn{6}{|c|}{ Apoptotic cell quantification (Caspase- $3^{+}$) } \\
\hline \multirow[t]{3}{*}{ E75 } & 1 & + & + & +++ & \\
\hline & 2 & + & + & ++ & \\
\hline & 3 & + & + & ++ & \\
\hline \multirow[t]{3}{*}{ E75CV1 } & 1 & + & + & + & + \\
\hline & 2 & + & ++ & + & + \\
\hline & 3 & + & + & + & + \\
\hline \multirow[t]{3}{*}{ Control } & 1 & + & + & + & + \\
\hline & 2 & + & + & + & + \\
\hline & 3 & + & + & + & + \\
\hline \multicolumn{6}{|l|}{ (C) } \\
\hline \multicolumn{6}{|c|}{ ASFV Antigen detection $\left({\left.\mathrm{p} 30^{+}\right)}^{+}\right.$} \\
\hline \multirow[t]{3}{*}{ E75 } & 1 & + & ++ & +++ & \\
\hline & 2 & - & + & ++ & \\
\hline & 3 & - & ++ & +++ & \\
\hline \multirow[t]{3}{*}{ E75CV1 } & 1 & + & - & + & + \\
\hline & 2 & - & - & + & + \\
\hline & 3 & + & + & - & ++ \\
\hline
\end{tabular}

Results were quantified as follows: $(-)$ no detection, $(+)$ low, $(++)$ moderate and $(+++)$ high amounts

modulated throughout the infections. Interestingly, differences became evident as early as at day $1 \mathrm{pi}$, before the virus was detectable in the tissue (Figure 5B). Thus, compared with the 10 genes significantly up and downregulated by day 1 pi with E75CV1, E75 only up-regulated 4, namely: $I L-12 p 40, T G F-\beta R 1, T N F-\alpha$ and $I L-21$, with key activation markers such as $\mathrm{sCD} 163, I F N-\gamma$ and IL-4 showing tendency towards being down-regulated (Figure 6A). This tendency totally reverted through the infection course and by day 7 pi the activation of a massive number of immune mediators was observed as demonstrated in here with the significant up-regulation of: $I L-5, D E F B 2, T L R-3, I L-6, I L-8, I L-1 \beta, I L-21, I L-23$ and $I L-10$; coinciding with the cytokine storm described 


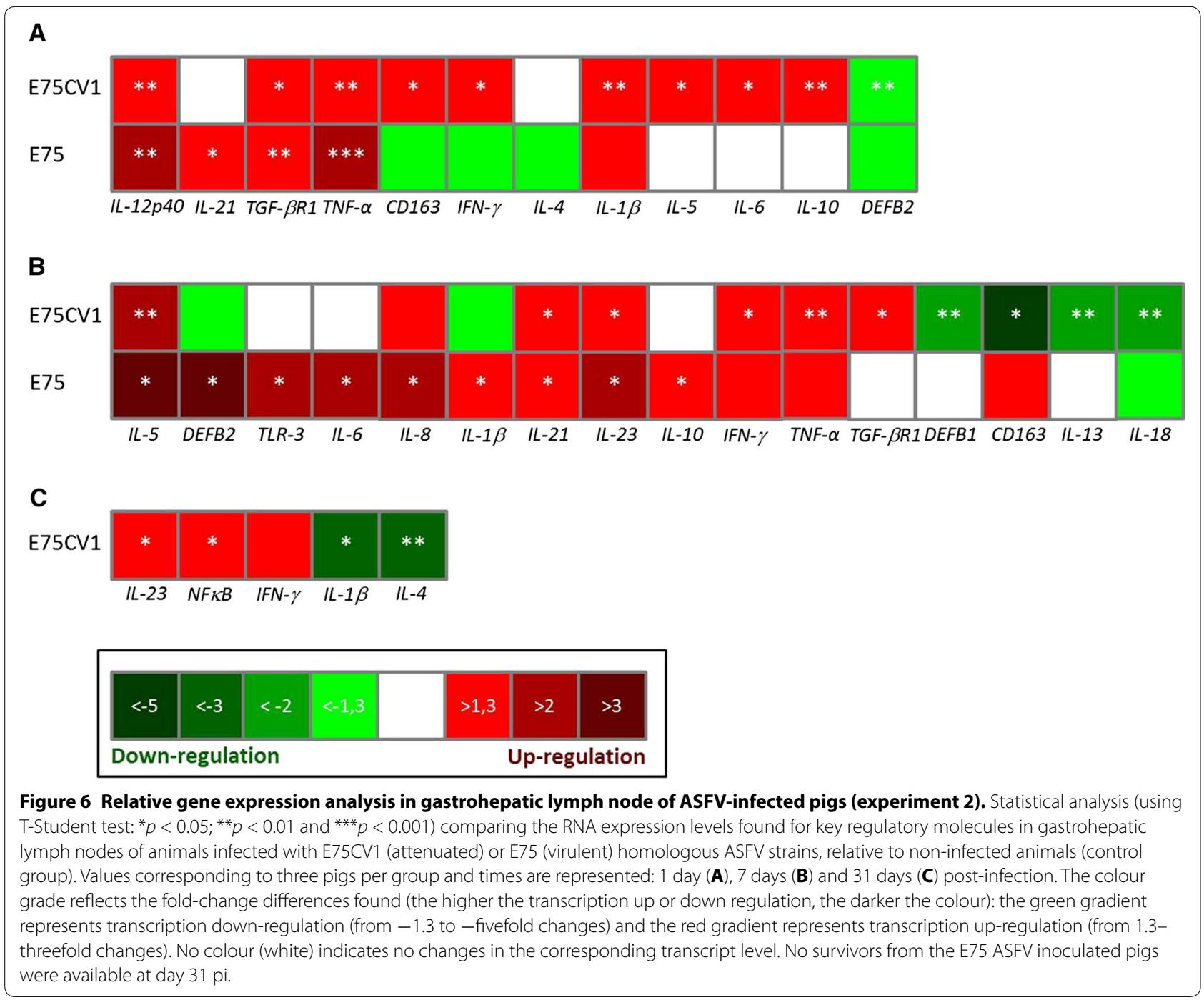

during the terminal phase of acute ASF [36] (Figure 6B). The transcription profile observed in the gastrohepatic lymph nodes of E75CV1-infected pigs showed an inverted cytokine response when compared to that of E75. Converse to that described for E75, E75CV1 efficiently activated an innate immune response detectable at day 1 pi with the significant up-regulation of $C D 163$, $I L-1 \beta, I F N-\gamma, I L-5, I L-6, I L-12 p 40, T N F-\alpha, I L-10$ and TGF- $\beta R 1$; most probably contributing to control of the first rounds of E75CV1-replication (Figure 6A). Confirming the inverse tendency described for E75, a more equilibrated immunological balance was observed with the progression of the E75CV1-infection, with 6 genes showing significant transcription up-regulation at day 7 pi: IFN- $\gamma, I L-5, T N F-\alpha, T G F-\beta R 1, I L-21, I L-23$ and 4 extra genes showing a significant down-regulation: $D E F B 1$, CD163, $I L-13$ and $I L-18$ (Figure 6B). Finally, pigs surviving the infection with E75CV1 showed a very consistent signature characterized by the up-regulation of $I L-23$, $I F N-\gamma$ and $N F \kappa B$ and the down-regulation of $I L-1 \beta$ and IL-4 (Figure 6C).

\section{E75CV1, an ideal model to understand the mechanisms involved in protection against homologous lethal challenge}

Once the optimal dose of E75CV1 i.m.i. was confirmed (Experiment 1), a final experiment was performed to evaluate its protective potential (Experiment 3). Confirming the results obtained in experiments 1 and 2, all pigs ( 8 out of 8,4 animals per box) i.m.i. with $10^{4}$ HAU of E75CV1 survived the infection without significant ASF clinical signs and showing none or low fever and viremia peaks that resolved by day 28 pi, coinciding with the presence of a high level of ASFV-specific antibodies and a large number of ASFV-specific T-cells as measured by ELISA and IFN $\gamma$-ELISPOT, respectively 
(data not shown). At this time point, all pigs in BOX-1 were challenged with a lethal dose of E75 and all animals in BOX-2 with a lethal dose of the BA71 virus strain.

E75CV1 infected animals rendered $100 \%$ of protection against the homologous E75 lethal challenge and importantly, the protection afforded was complete since no ASF-clinical signs including fever (Figure 7A), viremia (Figure $7 \mathrm{~B}$ ) and nasal viral excretion (Figure $7 \mathrm{C}$ ) were observed at any time in any of the inoculated animals. Additionally, no ASF-compatible lesions were detected in any of the animals at necropsy, while control animals behaved as expected: severe signs of ASF, severe ASFcompatible lesions found at necropsy time and high virus titres (in blood and nasal swabs) detectable from day 3 pi (Figures 7A, B and C). The control of the infection by pigs vaccinated with $10^{4} \mathrm{HAU}_{50}$ of E75CV1 correlated with the control of the cytokine storm typically triggered by virulent ASFV strains such as E75. Thus, the levels of IFN- $\alpha$ (Figure 8A) and TNF- $\alpha$ (Figure 8B) in pig sera remained at very low or undetectable levels in protected animals, while control animals showed an exponential increase in the sera levels of both cytokines after lethal challenge with the homologous E75 virulent ASFV strain, as was previously described, at least for TNF- $\alpha$ [37]. Besides these two cytokines, several other soluble factors were found at high levels in sera from severely ASF-affected pigs by day 7 pi with E75, including IL-12 and IL-1 $\beta$ (data not shown) and for the first time, also for sCD163 (Figure 8C), an activation macrophage marker that has been associated with several chronic inflammatory diseases, sepsis, and more recently also with certain haemorrhagic fever diseases caused by viruses [38].

Conversely, pre-immunization with E75CV1 rendered poor protection against BA71 lethal challenge. Two of the animals (50\%) reached viremia levels (Figure 9A) and nasal viral excretion titres (Figure 9B) indistinguishable from those found in control pigs, while the other 2 pigs showed a delay in the appearance of viremia (from day 3 to day $5 \mathrm{pi}$ ), reaching lower levels comparing with control group. Moreover, all the animals suffered from severe clinical signs of ASF, being sacrificed at day 7 pi for ethical reasons. At the time of necropsy it was not possible to differentiate the controls and the vaccinated animals (data not shown).

Intriguingly, sera and PBMCs isolated from pigs surviving E75CV1 (day 28 pi), equally recognized E75 and BA71 in vitro, at least using the home-made ELISA and IFN $\gamma$-ELISPOT assays and again, sera from these
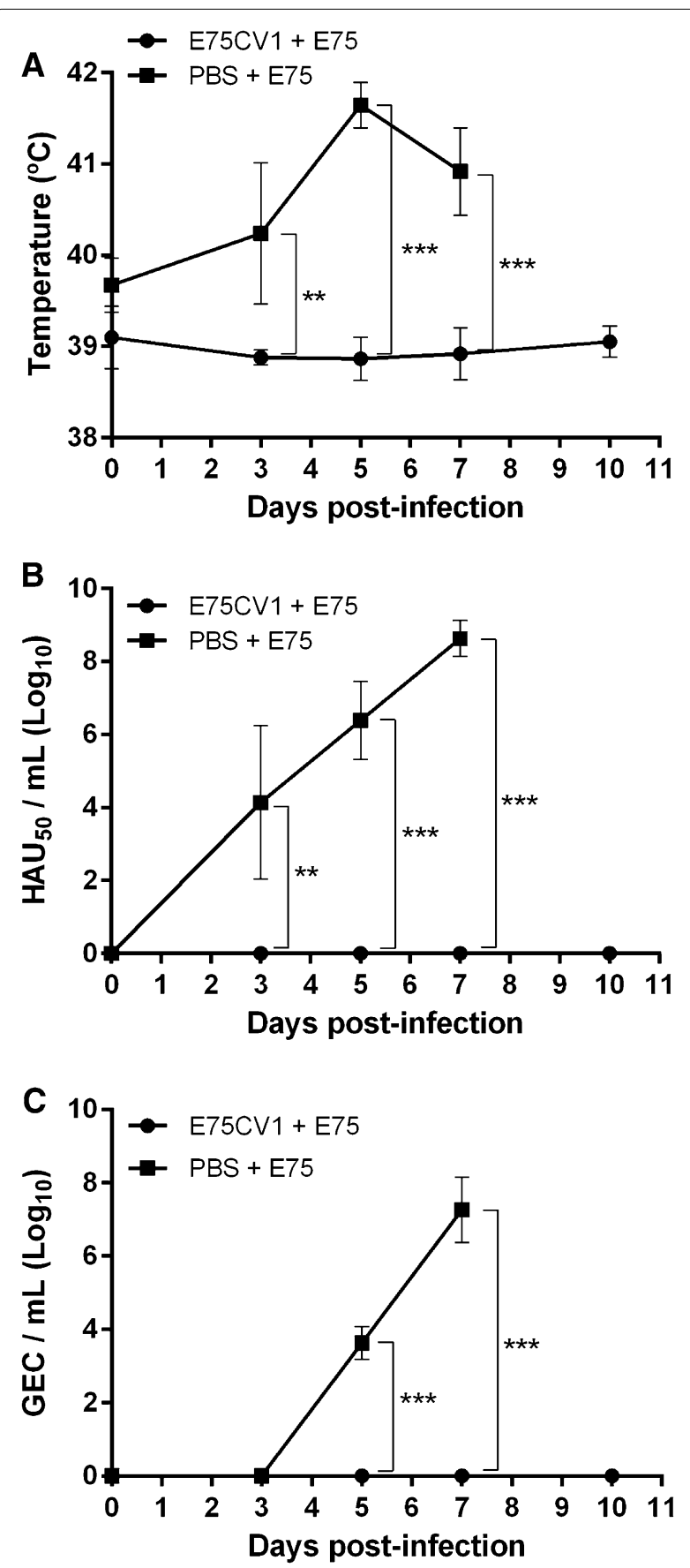

Figure 7 Inoculation of E75CV1 confers protection against homologous E75 lethal challenge (Box 1 from experiment 3). Groups of four pigs were either inoculated with $10^{4} \mathrm{HAU}_{50} \mathrm{E} 75 \mathrm{CV} 1$ or non-immunized (control) and 31 days later were challenged with a lethal dose of $10^{4} \mathrm{HAU}_{50}$ of E75. The ASFV infection was montitored by: rectal temperature $(\mathbf{A})$, virus detection in sera by hemadsorption (B) and nasal excretion by means of $\mathrm{PPCR}(\mathbf{C})$. The graphs show the average values of each group and the standard deviations (** $p<0.01$ and $\left.{ }^{* *} p<0.001\right)$. 


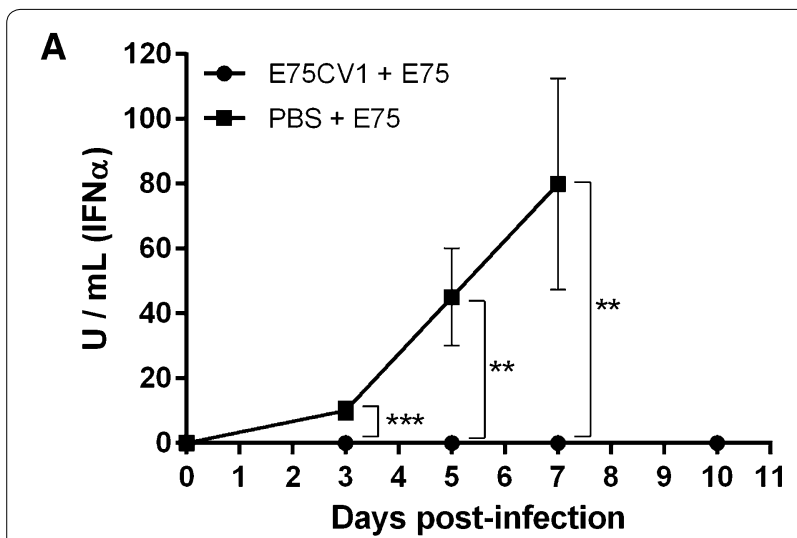

$\mathbf{B}$
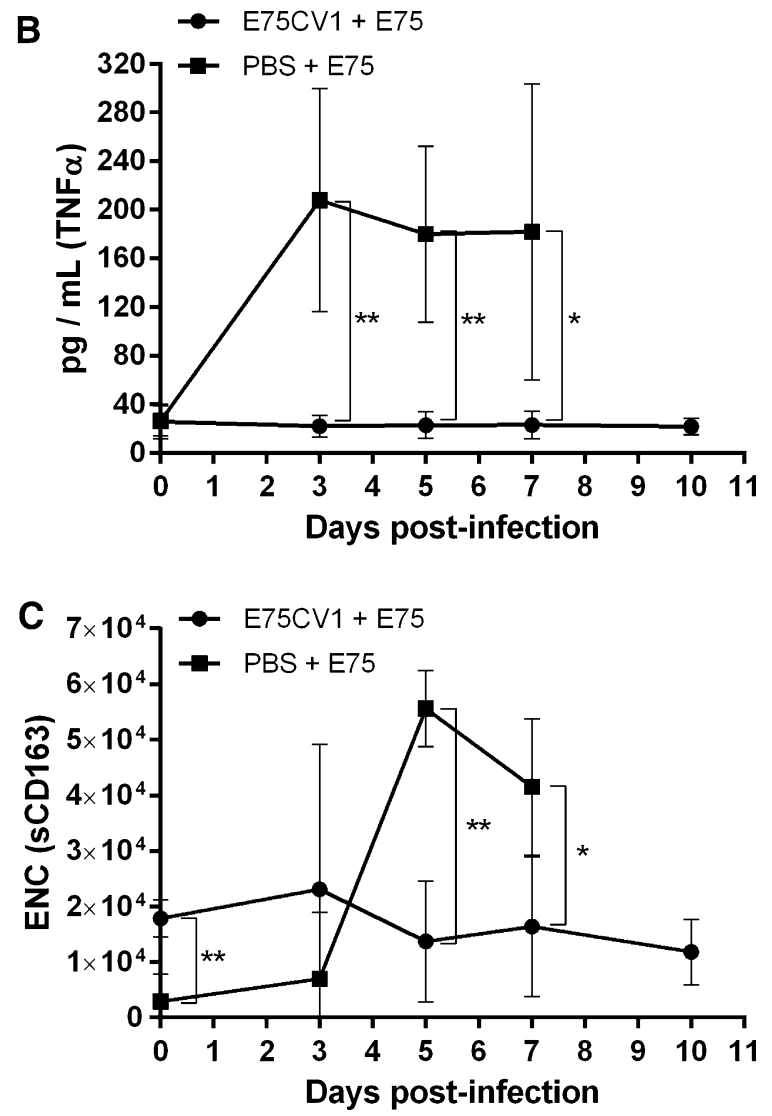

Figure 8 Inoculation of E75CV1 protects against the cytokine storm provoked by homologous E75 lethal challenge (Box 1 from experiment 3). Groups of four pigs were either inoculated with $10^{4} \mathrm{HAU}_{50} \mathrm{E} 75 \mathrm{CV} 1$ or non-immunized (control) and 31 days later were challenged with a lethal dose of $10^{4} \mathrm{HAU}_{50}$ E75. The delivery of cytokines and soluble cellular factors to the sera of the infected pigs was measured throughout the ASFV-challenge by specific ELISAs for: IFN- $a(\mathbf{A})$, TNF- $a(\mathbf{B})$ and sCD163 (C). Graphs show average values and standard deviations per group $\left({ }^{*} p<0.05 ;{ }^{* *} p<0.01\right.$ and $\left.{ }^{* *} p<0.001\right)$.

animals were not capable of inhibiting the ASFV-infection in alveolar macrophages (data not shown). Aiming to further explore the mechanisms that could explain
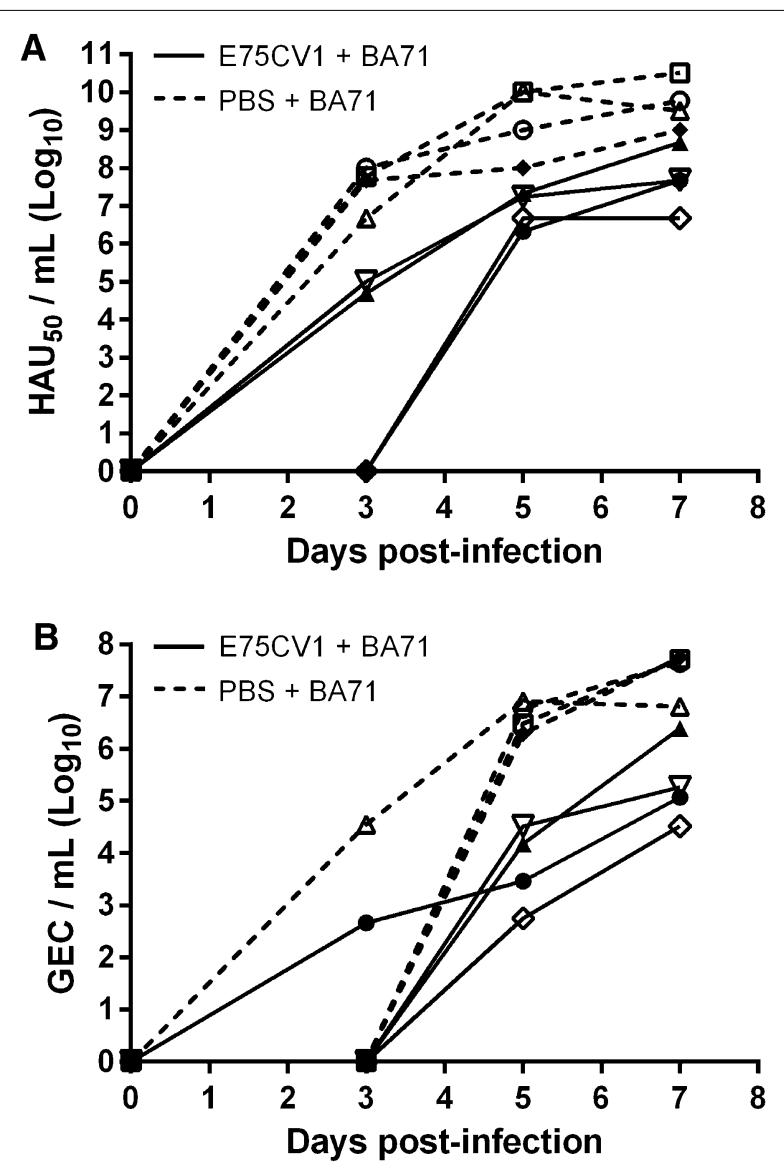

Figure 9 Inoculation of E75CV1 does not confer protection against heterologous BA71 lethal challenge (Box 2 from experiment 3). Groups of four pigs were either inoculated with $10^{4} \mathrm{HAU}_{50}$ E75CV1 (solid lines) or non-immunized (control, discontinuous lines) and 31 days later were challenged with a lethal dose of $10^{3} \mathrm{HAU}_{50}$ BA71. The ASFV infection was monitored by: ASFV detection in sera by hemadsorption $(\mathbf{A})$ and nasal excretion by means of $\mathrm{qPCR}(\mathbf{B})$. The graphs show the values corresponding to individual pigs.

E75-homologous protection and the lack of cross-protection against BA71, the PBMCs from animals infected with E75CV1 at day 28 pi were subjected to an in vitro CFSE-proliferation assay using either E75 or BA71 as specific stimuli for three days. Interestingly, immunization with the attenuated E75CV1 induced double positive $\mathrm{CD} 4^{+} / \mathrm{CD} 8^{\text {low }} \mathrm{T}$-cells capable of specifically recognizing both viruses, E75 and BA71 (Figure 10). In clear contrast, their single positive $\mathrm{CD} 8^{\text {high }} \mathrm{T}$-cells specifically proliferated almost exclusively in response to the homologous E75 virus, with the heterologous BA71 provoking a poor $\mathrm{CD} 8^{+} \mathrm{T}$-cell stimulation (Figure 10). A poor stimulation was also observed in response to both viruses for the single positive $\mathrm{CD} 4^{+} \mathrm{T}$-cells (Figure 10). 


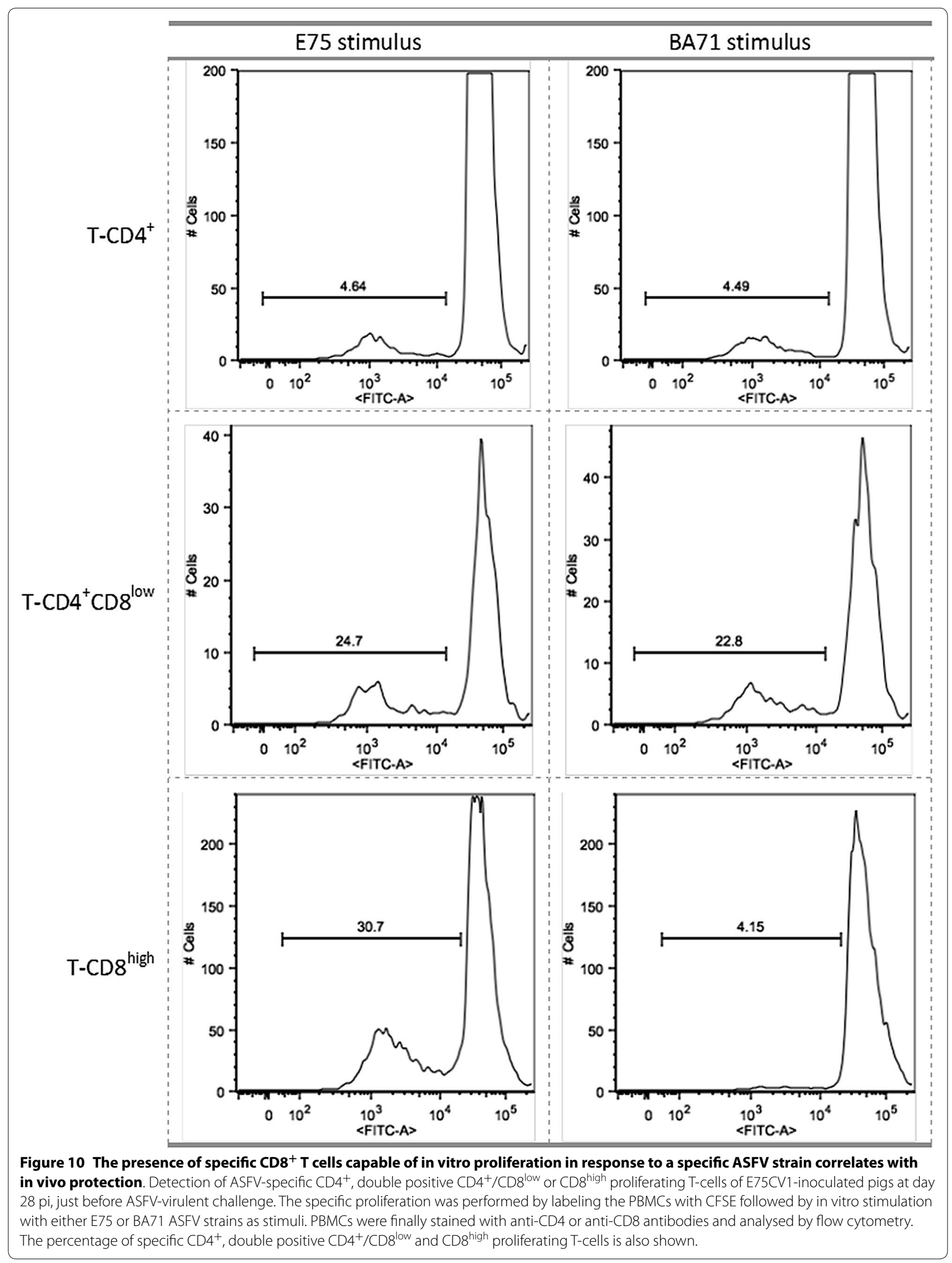




\section{Discussion}

The fine balance observed between surviving and death after ASFV infection seems to rest on multiple factors, including the pathogenicity of a particular ASFV strain, the initial viral dose received by the pig and the health status of the particular animal. Thus, receiving ten times more ASFV than the optimal dose of the cell culture adapted E75CV1 provoked the death of $50 \%$ of the pigs, corresponding with their incapability to control the initial rounds of replication as demonstrated with the detection of early viremia from day 5 pi, 3 days before surviving pigs. The fact that infection with $10^{4} \mathrm{HAU}_{50}$ of the virulent E75 strain also coincided with early viremia detectable from days $3-5 \mathrm{pi}$, correlating with an impaired recognition by the immune system very early after the infection (see below), allows us to hypothesize that a similar scenario could also explain the fate between surviving and death after i.m.i. with high doses of E75CV1 (2 out of 4 pigs dying after i.m.i. with $10^{5} \mathrm{HAU}_{50}$ of the virus). In agreement with this hypothesis, the viremia and the clinical signs observed and the postmortem lesions found in these two pigs were indistinguishable from those occurring after E75-infection. The unexpected results obtained after inoculating pigs with the lower dose of E75CV1 $\left(100 \mathrm{HAU}_{50}\right)$ might be explained by direct in contacttransmission, most probably with the two pigs succumbing to the high infectious-dose of E75CV1. Even if this was the scenario, it accurately reflects what might occur under field conditions, with a proportion of naïve pigs becoming severely infected by exposure to large amounts of a live attenuated vaccine. Increasing biosafety tests for LAV prototypes might be mandatory in the future if they are to be commercialized. The results recently obtained with E75CV1 [15] and also observed with the OURT88/3 ASFV attenuated strain [12], allow the assumption that the use of specific pathogen free (SPF)-pigs could become an ideal in vivo model for evaluating the biosecurity of future live attenuated ASFV as vaccines. Infection of SPF-pigs with the intermediate optimal dose of E75CV1, albeit safe for farm pigs, resulted lethal for $100 \%$ of the SPF-animals [15]. The reasons behind the enhanced sensitivity of SPF pigs to attenuated ASFV strains could also partially explain the vaccine escapes observed under field conditions in the past [13]. The existence of residual virulence in ASFV attenuated strains has been described not only for naturally attenuated strains, such as E75CV1 and OURT 88/3 [12], but also for modified LAV generated by targeted depletion of virulent factors [39] and on many occasions this becomes complicated due to secondary infections attributable to the immune suppression induced by the virus.

With the aim of understanding the molecular mechanisms involved in attenuation of E7CV1, we are currently in the process of sequencing E75CV1. The availability of the E75 complete sequence (GenBank: FN557520) should facilitate the identification of the molecular changes in the genome of E75CV1 in comparison to its closest relative, thus contributing to better define virulence factors. Much effort has been made in the past with distantly related virulent and attenuated viruses and more recently, with related strains with different virulence facilitating the comparison [40]. These results have recently been extended to a more refined study helping to unmask the genome changes occurring during the adaptation of the virulent Georgia 2007 ASFV strain to Vero cell and subsequent attenuation [41].

We believe that performing comparative pathogenesis studies with two homologous strains with a unique origin, further validates the results obtained. Quantitative PCR results demonstrated the differential transcription kinetics existing between the attenuated and the virulent ASFV-strains. The infection with E75 shows a transcription profile quantitatively and qualitatively different from E75CV1 early after the infection. Thus, compared with the 10 genes significantly up and down-regulated by day 1 pi with E75CV1, E75 only up-regulated 4 of them, namely: $I L-12 p 40, T G F-\beta R 1, T N F-\alpha$ and $I L-21$; the last not being significantly regulated with $\mathrm{E} 75 \mathrm{CV} 1$ infection. The reduced number of immune modulators triggered at day 1 pi might help explaining the failure of the innate immune system to detect and control the first rounds of virus replication, thus allowing the rapid spread of the virus to lymphoid tissues, blood and nasals secretions. The lack of early recognition (day 1 pi) of the E75 virulent strain by the immune system might correlate with the observed down-regulation tendency of CD163, a putative ASFV receptor [42]. Conversely to what has been shown for E75CV1 the progression of the E75-infection resulted in a dramatic imbalance of the immune system by day 7 pi, with the significant up-regulation of 9 genes, namely: $I L-5, I L-1 \beta, I L-6, I L-8, I L-10, I L-21, I L-23, D E F B 2$ and $T L R-3$. Surprisingly, the TLR-3 gene was significantly and exclusively up-regulated at day $7 \mathrm{pi}$, perhaps reflecting the incapability of the TLR-3 antagonist present in ASFV [43] to keep the TLR-3 signaling pathway under control any longer. TLR-3, an Innate Pattern Recognition Receptor (IPRR) has been described as an efficient virus-sensor that could trigger friendly or unfriendly transduction cascades. The number and level of genes up-regulated at day 7 pi is unexpectedly high taking into account the damage suffered by the gastrohepatic lymph node, showing an almost unrecognizable architecture with massive cellular destruction. The dramatic increase found in sera of almost all the immune mediators tested: TNF- $\alpha$, IFN- $\alpha$, IL-12, IL-1 $\beta$ and sCD163 confirm the soluble factor storm suffered by acutely infected pigs in the latter 
phases of infection, most probably reflecting the massive tissue destruction found. Therefore, the dramatic activation of the immune system at day 7 pi might reflect the massive and disseminated fatal infection rather than a defensive mechanism. Unfortunately, the late detection of significantly high levels of sCD163 in sera at very late times makes its future use as an early diagnostic marker for ASFV unlikely. The presence of sCD163 in sera could however give new insight into understanding ASFV pathogenesis, perhaps playing an immunoregulatory role.

Conversely, the same viral dose of E75CV1 provoked the immediate activation of the immune system, reflecting most probably an efficient priming of the innate immune system, a key event for further mounting an efficient adaptive immune response, detectable at late time points post-infection. A careful dissection of the transcription profile by day 1 pi in tissues from E75CV1infected pigs, allowed the confirmation of the significant up-regulation of $C D 163, I L-1 \beta, I F N-\gamma, I L-5, I L-6, I L-10$, $I L-12 p 40, T N F-\alpha$ and TGF- $\beta R 1$ and the down-regulation of DEFB2, immediately after E75CV1 infection. The up-regulation of CD163 has been associated with monocytes maturation into macrophages, and fits with the ability of ASFV to interact with the surface CD163 for viral entry [42]. The role of CD163 as receptor for ASFV entry has been proposed but not universally supported since reports demonstrated efficient infection of macrophages that do not express CD163 [44]. Regardless of this, the virus interaction with CD163 and other cell surface molecules most probably trigger the overexpression of the genes coding several pro-inflammatory cytokines: $I L-1 \beta, I F N-\gamma, I L-5, I L-6, I L-12 p 40$ and TNF$\alpha$; and also some anti-inflammatory mediators such as $I L-10$ and TGF- $\beta R 1$ that might contribute to controlling the first rounds of virus replication while avoiding harmful inflammation. With the progression of the infection a more equilibrated immunological balance is observed, with 6 genes showing significant transcription up-regulation: IFN- $\gamma, I L-5, T N F-\alpha, T G F-\beta R 1, I L-21$ and $I L-23$ and 4 extra genes showing significant downregulation: $D E F B 1, C D 163, I L-13$ and $I L-18$. By day 31 pi, once the E75CV1 infection has been resolved and the memory specific $B$ and $\mathrm{T}$-cell responses have been established, a very tight regulation of the immune response was observed with only 2 genes being significantly upregulated: $I L-23$ and $N F K B$; and another two significantly down-regulated: $I L-1 \beta$ and $I L-4$, signature of Th 17 -like responses. The continuous down-regulation suffered by the $I L-4$ transcript reached its maximum level and significance at day 31 pi with E75CV1, coinciding with significant up-regulation of $I L-23$ that in turn has been described to promote the Th17 switch [45]. This together with the continuous activation of $I F N-\gamma$ and TGF- $\beta R 1$ throughout E75CV1 infection could also contribute to the continuous transformation of Th1 to Th17 cells, also previously described [46]. Th17 were first described as a CD4 ${ }^{+}$T-cell subset associated with chronic inflammatory processes, autoimmunity, allergy and transplant rejection [47]. Today we know that this is true if inappropriate, excessive, and non-specific Th17 effector responses are triggered, while on other occasions the induction of specific Th17/Th1 $\left(\mathrm{IL}-17^{+} / \mathrm{IFN}-\gamma^{+}\right.$ cells) could exert beneficial effects. Thus, $\mathrm{T}(\mathrm{H}) 1 / \mathrm{T}(\mathrm{H}) 17$ have been postulated as key cell subsets to fight against infections such as tuberculosis [48]. Thus, lacking $(\mathrm{T}(\mathrm{H}) 1 / \mathrm{T}(\mathrm{H}) 17)$-cells has been described as a risk factor for the development of active tuberculosis in patients with HIV-1 infection and has been proposed as a useful biomarker in the development of tuberculosis vaccines. Further work will be needed to confirm the specificity and the role of Th17 cells in protection. The partial transcription profile shown here will be completed by performing complementary micro array and proteomic assays (work in progress).

As described in the introduction together with the innate immune responses, both specific $B$ and $\mathrm{T}$-cell responses play important roles in the protection afforded [30], these also being efficiently primed by our E75CV1 model. Unfortunately, all attempts to demonstrate the presence of specific antibodies capable of inhibiting the ASFV infection in vitro failed [28]. Similarly, the identical sequences of the E75 and BA71 haemagglutinin also failed to define the cross protection failure using a differential hemadsorption inhibition assay, as recently postulated for predicting the efficacy of ASFV vaccines [49]. Although no significant differences were observed by IFNy-ELISPOT in response to the in vitro stimulation with either the homologous E75 or the heterologous BA71 viruses, we could not rule-out that these differences exist, as has been previously reported [12]. Technical limitations of our home-made IFN $\gamma$-ELISPOT assay performed with half a million PBMCs, did not allow a precise quantification of the specific spots found in response to each specific stimuli. Independent of these differences, one of the most relevant conclusions of the present work is the definition of a new in vitro correlation for ASFV protection to be added to the ones that already exist. The fact that $\mathrm{CD} 4^{+}$ and double positive $\mathrm{CD} 4^{+} / \mathrm{CD} 8^{\text {low }} \mathrm{T}$-cells, defined as memory T-cells [30] indistinguishably proliferated in response to both homologous and heterologous virus fits with the IFN $\gamma$-ELISPOT data presented here. Conversely, the strong correlation between protection and in vitro recognition of strain-specific $C D 8^{\text {high }}$ T-cells, cytotoxic T-cells [30] is novel and might have 
important implications for the future design of vaccines. Cross-protective vaccines should be able to induce specific CTL responses against common antigens, an element that seems to be impaired in the LAV tested so far against ASFV. It has recently been published results demonstrating the establishment of a strong $\mathrm{CD}^{+} \mathrm{T}$-cell immunodominance during ASFV recovery in vivo that could be overcome by prior immunization with subunit vaccines [30], a fact previously described for many pathogens. Several can be the reasons explaining the narrow repertoire of specific $\mathrm{CD}^{+}$T-cells induced, most probably being multifactorial and regulated by IFN- $\gamma$ as explained for many other viruses [50]. The intrinsic mechanisms explaining ASF-immunodominance are being further studied with the aim of extracting useful lessons for future vaccine developments against ASFV.

\section{Competing interests}

The authors declare that they have no competing interests.

\begin{abstract}
Authors' contributions
$\mathrm{AL}$ is the paper's main task force. PLM has collaborated in the in vivo experiments under AL and FA supervision. AJM established the GPCRs for key swine immune mediators under the supervision of JJG and AM; experts in swine genomics and proteomics. MB has designed and supervised the work involving qPCRs for ASFV detection. JA established the proliferation assay presented in the manuscript. IGC and JS have performed all the pig necropsies and quantified the ASF-compatible lesions found. MLS contribution made possible all the work performed with the BA71 strain and played a key role during the reviewing process of the manuscript. JD developed and performed the sCD163 assay. FR has been in charge of the experimental designing and together with AL of the writing of the manuscript. All authors read and approved the final manuscript.
\end{abstract}

\section{Acknowledgements}

This work has been funded by the Spanish Government (project reference numbers AGL201022229 and AGL201348998C21R). Anna Lacasta and Paula López-Monteagudo were financially supported by an FPU fellowship and an FPI fellowship, respectively, both from the Spanish Government. We thank Marie Frédérique Lepotier (ANSES), Esther Blanco (CISA-INIA) and Javier M. Rodríguez (ISCIII) and Miquel Nofrarías, Sergio López and Enric Vidal (CReSA) for their professional help and advice, María Jesús Navas and Mónica Pérez for their technical help, and the rest of CReSA's personnel (especially the BSL-2 and BSL-3 animal care personnel) for their support. We thank Kevin Dalton for editing the manuscript.

\footnotetext{
Author details

${ }^{1}$ Centre de Recerca En Sanitat Animal (CReSA), Institut de Recerca i Tecnologia Agroalimentàries (IRTA), Campus UAB, Bellaterra, 08193 Barcelona, Spain. ${ }^{2}$ International Livestock Research Intitute (ILRI), 00100 Nairobi, Kenya. ${ }^{3}$ Instituto de Agricultura Sostenible, Campus Alameda del Obispo, 14080 CSIC Córdoba, Spain. ${ }^{4}$ Departament de Sanitat i Anatomia Animals, Universitat Autònoma de Barcelona (UAB), Bellaterra, 08193 Barcelona, Spain. ${ }^{5}$ INRA, UMR, 1313, Génétique Animale et Biologie Intégrative, 78352 Jouy-en-Josas, France. ${ }^{6}$ Universitat Pompeu Fabra, 08003 Barcelona, Spain. ${ }^{7}$ WorldPathol Ltd. Co., 50005 Saragossa, Spain. ${ }^{8}$ Centro de Biología Molecular Severo Ochoa (Consejo Superior de Investigaciones Científicas-Universidad Autónoma de Madrid), 28049 Madrid, Spain. ${ }^{9}$ Departamento de Biotecnologia, INIA, 28040 Madrid, Spain. ${ }^{10}$ Grupo de Genómica y Mejora Animal, Departamento de Genética, Facultad de Veterinaria, Universidad de Córdoba, Campus de Rabanales, Ed. C-5, 14071 Córdoba, Spain.
}

Received: 6 July 2015 Accepted: 12 October 2015

Published online: 20 November 2015

\section{References}

1. Costard S, Jones BA, Martinez-Lopez B, Mur L, de la Torre A, Martinez M, Sanchez-Vizcaino F, Sanchez-Vizcaino JM, Pfeiffer DU, Wieland B (2013) Introduction of African swine fever into the European Union through illegal importation of pork and pork products. PLoS One 8:e61104

2. De la Torre A, Bosch J, Iglesias I, Munoz MJ, Mur L, Martinez-Lopez B, Martinez M, Sanchez-Vizcaino JM (2015) Assessing the risk of African swine fever introduction into the European Union by wild boar. Transbound Emerg Dis 62:272-279

3. Sanchez-Vizcaino JM, Mur L, Martinez-Lopez B (2012) African swine fever: an epidemiological update. Transbound Emerg Dis 59(Suppl 1):27-35

4. Edelsten RM, Chinombo DO (1995) An outbreak of African swine fever in the southern region of Malawi. Rev Sci Tech 14:655-666

5. Manso Ribeiro J, Roza Azevedo JA, Teixeira MJO, Braco Forte MC, Rodrigues Ribeiro AM, Oliveira F, Noronha E, Grave Pereira C, Dias Vigario J (1958) Peste Porcine provoquée par une souche différente (Souche L) de la souche classique. Bull Off Int Epiz 50:516-534 (in French)

6. Beltran-Alcrudo D, Lubroth J, Depner K, De La Rocque S (2008) African swine fever virus in the Caucasus. EMPRES watch FAO, Rome. Accessed 10th January 2015

7. Forman AJ, Wardley RC, Wilkinson PJ (1982) The immunological response of pigs and guinea pigs to antigens of African swine fever virus. Arch Virol 74:91-100

8. Mebus CA (1988) African swine fever. Adv Virus Res 35:251-269

9. Montgomery RE (1921) On a form of swine fever occurring in British East Africa (Kenya colony). J Comp Pathol 34:59-191

10. Stone SS, Hess WR (1967) Antibody response to inactivated preparations of African swine fever virus in pigs. Am J Vet Res 28:475-481

11. Ruiz Gonzalvo F, Carnero E, Bruvel V (1983) Immunological responses of pigs to partially attenuated African swine fever virus and their resistance to virulent homologous and heterologous viruses. In: Wilkinson PJ (ed) African Swine Fever. Proc. EUR 8466 EN, CEC/FAO., Sardinia, pp. 2066-2216

12. King $K$, Chapman D, Argilaguet JM, Fishbourne E, Hutet $E$, Cariolet $R$, Hutchings G, Oura CA, Netherton CL, Moffat K, Taylor G, Le Potier MF, Dixon LK, Takamatsu HH (2011) Protection of European domestic pigs from virulent African isolates of African swine fever virus by experimental immunisation. Vaccine 29:4593-4600

13. Manso Ribeiro J (1962) Déclaration sur la vaccination contre la Peste Porcine Africaine à la XXX' Session Générale de l'Office International des Epizooties. Bull Off Int Epiz 58:1031-1040 (in French)

14. Argilaguet JM, Perez-Martin E, Nofrarias M, Gallardo C, Accensi F, Lacasta A, Mora M, Ballester M, Galindo-Cardiel I, Lopez-Soria S, Escribano JM, Reche PA, Rodriguez F (2012) DNA vaccination partially protects against African swine fever virus lethal challenge in the absence of antibodies. PLoS One 7:e40942

15. Lacasta A, Ballester M, Monteagudo PL, Rodriguez JM, Salas ML, Accensi F, Pina-Pedrero S, Bensaid A, Argilaguet J, Lopez-Soria S, Hutet E, Le Potier MF, Rodriguez F (2014) Expression library immunization can confer protection against lethal challenge with African swine fever virus. J Virol 88:13322-13332

16. Neilan JG, Zsak L, Lu Z, Burrage TG, Kutish GF, Rock DL (2004) Neutralizing antibodies to African swine fever virus proteins p30, p54, and p72 are not sufficient for antibody-mediated protection. Virology 319:337-342

17. Wardley RC, Norley SG, Wilkinson PJ, Williams S (1985) The role of antibody in protection against African swine fever virus. Vet Immunol Immunopathol 9:201-212

18. Zsak L, Onisk DV, Afonso CL, Rock DL (1993) Virulent African swine fever virus isolates are neutralized by swine immune serum and by monoclonal antibodies recognizing a 72-kDa viral protein. Virology 196:596-602

19. Onisk DV, Borca MV, Kutish G, Kramer E, Irusta P, Rock DL (1994) Passively transferred African swine fever virus antibodies protect swine against lethal infection. Virology 198:350-354

20. Oura CA, Denyer MS, Takamatsu H, Parkhouse RM (2005) In vivo depletion of CD8 + T lymphocytes abrogates protective immunity to African swine fever virus. J Gen Virol 86:2445-2450

21. Escribano JM, Galindo I, Alonso C (2013) Antibody-mediated neutralization of African swine fever virus: myths and facts. Virus Res 173:101-109

22. Zhang F, Hopwood P, Abrams CC, Downing A, Murray F, Talbot R, Archibald A, Lowden S, Dixon LK (2006) Macrophage transcriptional responses following in vitro infection with a highly virulent African swine fever virus isolate. J Virol 80:10514-1052 
23. Galindo-Cardiel I, Ballester M, Solanes D, Nofrarias M, Lopez-Soria S, Argilaguet JM, Lacasta A, Accensi F, Rodriguez F, Segales J (2013) Standardization of pathological investigations in the framework of experimental ASFV infections. Virus Res 173:180-190

24. Argilaguet JM (2009) Desarrollo de nuevas estrategias vacunales frente a la peste porcina africana. Ph.D. Thesis, Universitat Auntònoma de Barcelona. Department of Animal Health

25. Argilaguet JM, Perez-Martin E, Gallardo C, Salguero FJ, Borrego B, Lacasta A, Accensi F, Diaz I, Nofrarias M, Pujols J, Blanco E, Perez-Filgueira M, Escribano JM, Rodriguez F (2011) Enhancing DNA immunization by targeting ASFV antigens to SLA-II bearing cells. Vaccine 29:5379-5385

26. Reed $L$, Muench H (1938) A simple method of estimating fifty per cent endpoint. Am J Hyg 27:493-497

27. Gallardo C, Soler A, Nieto R, Carrascosa AL, De Mia GM, Bishop RP, Martins C, Fasina FO, Couacy-Hymman E, Heath L, Pelayo V, Martin E, Simon A, Martin R, Okurut AR, Lekolol I, Okoth E, Arias M (2013) Comparative evaluation of novel African swine fever virus (ASF) antibody detection techniques derived from specific ASF viral genotypes with the OlE internationally prescribed serological tests. Vet Microbiol 162:32-43

28. Ruiz Gonzalvo F, Carnero ME, Caballero C, Martinez J (1986) Inhibition of African swine fever infection in the presence of immune sera in vivo and in vitro. Am J Vet Res 47:1249-1252

29. Banks HT, Sutton KL, Thompson WC, Bocharov G, Doumic M, Schenkel T, Argilaguet J, Giest S, Peligero C, Meyerhans A (2011) A new model for the estimation of cell proliferation dynamics using CFSE data. J Immunol Methods 373:143-160

30. Takamatsu HH, Denyer MS, Lacasta A, Stirling CM, Argilaguet JM, Netherton CL, Oura CA, Martins C, Rodriguez F (2013) Cellular immunity in ASFV responses. Virus Res 173:110-121

31. Collado-Romero M, Arce C, Ramirez-Boo M, Carvajal A, Garrido JJ (2010) Quantitative analysis of the immune response upon Salmonella typhimurium infection along the porcine intestinal gut. Vet Res 41:23

32. Collado-Romero M, Martins RP, Arce C, Moreno A, Lucena C, Carvajal A Garrido JJ (2012) An in vivo proteomic study of the interaction between Salmonella Typhimurium and porcine ileum mucosa. J Proteomics 75:2015-2026

33. Vandesompele J, De Preter K, Pattyn F, Poppe B, Van Roy N, De Paepe A, Speleman F (2002) Accurate normalization of real-time quantitative RT-PCR data by geometric averaging of multiple internal control genes. Genome Biol 3: RESEARCH0034

34. Livak KJ, Schmittgen TD (2001) Analysis of relative gene expression data using real-time quantitative PCR and the 2(-Delta Delta C(T)) Method. Methods 25:402-408

35. Perez C, Ortuño E, Gómez N, García-Briones M, Álvarez B, Martínez de la Riva P, Alonso F, Revilla C, Domínguez J, Ezquerra A (2008) Cloning and expression of porcine CD163: its use for characterization of monoclonal antibodies to porcine CD163 and development of an ELISA to measure soluble CD163 in biological fluids. Span J Agric Res 6:59-72

36. Zakaryan H, Cholakyans V, Simonyan L, Misakyan A, Karalova E, Chavushyan A, Karalyan Z (2015) A study of lymphoid organs and serum proinflammatory cytokines in pigs infected with African swine fever virus genotype II. Arch Virol 160:1407-1414

37. Gomez del Moral M, Ortuno E, Fernandez-Zapatero P, Alonso F, Alonso C, Ezquerra A, Dominguez J (1999) African swine fever virus infection induces tumor necrosis factor alpha production: implications in pathogenesis. J Virol 73:2173-2180
38. Wang J, Guo W, Du H, Yu H, Jiang W, Zhu T, Bai X, Wang P (2014) Elevated soluble CD163 plasma levels are associated with disease severity in patients with hemorrhagic fever with renal syndrome. PLoS One 9:e112127

39. Borca MV, Carrillo C, Zsak L, Laegreid WW, Kutish GF, Neilan JG, Burrage TG, Rock DL (1998) Deletion of a CD2-like gene, 8-DR, from African swine fever virus affects viral infection in domestic swine. J Virol 72:2881-2889

40. Portugal R, Coelho J, Hoper D, Little NS, Smithson C, Upton C, Martins C, Leitao A, Keil GM (2015) Related strains of African swine fever virus with different virulence: genome comparison and analysis. J Gen Virol 96:408-419

41. Krug PW, Holinka LG, O'Donnell V, Reese B, Sanford B, Fernandez-Sainz I, Gladue DP, Arzt J, Rodriguez L, Risatti GR, Borca MV (2015) The progressive adaptation of a georgian isolate of African swine fever virus to vero cells leads to a gradual attenuation of virulence in swine corresponding to major modifications of the viral genome. J Virol 89:2324-2332

42. Sanchez-Torres C, Gomez-Puertas P, Gomez-del-Moral M, Alonso F, Escribano JM, Ezquerra A, Dominguez J (2003) Expression of porcine CD163 on monocytes/macrophages correlates with permissiveness to African swine fever infection. Arch Virol 148:2307-2323

43. de Oliveira VL, Almeida SC, Soares HR, Crespo A, Marshall-Clarke S, Parkhouse RM (2011) A novel TLR3 inhibitor encoded by African swine fever virus (ASFV). Arch Virol 156:597-609

44. Lithgow P, Takamatsu H, Werling D, Dixon L, Chapman D (2014) Correlation of cell surface marker expression with African swine fever virus infection. Vet Microbiol 168:413-419

45. Guenova E, Skabytska Y, Hoetzenecker W, Weindl G, Sauer K, Tham M, Kim KW, Park JH, Seo JH, Ignatova D, Cozzio A, Levesque MP, VolzT, Koberle M, Kaesler S, Thomas P, Mailhammer R, Ghoreschi K, Schakel K, Amarov B, Eichner M, Schaller M, Clark RA, Rocken M, Biedermann T (2015) IL-4 abrogates $T(\mathrm{H}) 17$ cell-mediated inflammation by selective silencing of IL-23 in antigen-presenting cells. Proc Natl Acad Sci U S A 112:2163-2168

46. Liu HP, Cao AT, Feng T, Li Q, Zhang W, Yao S, Dann SM, Elson CO, Cong Y (2015) TGF-beta converts Th1 cells into Th17 cells through stimulation of Runx1 expression. Eur J Immunol 45:1010-1018

47. Essakalli M, Brick C, Bennani N, Benseffaj N, Ouadghiri S, Atouf O (2010) The latest TH17 lymphocyte in the family of T CD4 + lymphocytes. Pathol Biol 58:437-443 (in French)

48. Clark S, Page E, Ford T, Metcalf R, Pozniak A, Nelson M, Henderson DC, Asboe D, Gotch F, Gazzard BG, Kelleher P (2011) Reduced T(H)1/T(H)17 CD4 T-cell numbers are associated with impaired purified protein derivative-specific cytokine responses in patients with HIV-1 infection. J Allergy Clin Immunol 128(838-846):e835

49. Malogolovkin A, Burmakina G, Titov I, Sereda A, Gogin A, Baryshnikova E, Kolbasov D (2015) Comparative analysis of African swine fever virus genotypes and serogroups. Emerg Infect Dis 21:312-315

50. Rodriguez F, Harkins S, Slifka MK, Whitton JL (2002) Immunodominance in virus-induced CD8(+) T-cell responses is dramatically modified by DNA immunization and is regulated by gamma interferon. J Virol 76:4251-4259

\section{Submit your next manuscript to BioMed Central and take full advantage of:}

- Convenient online submission

- Thorough peer review

- No space constraints or color figure charges

- Immediate publication on acceptance

- Inclusion in PubMed, CAS, Scopus and Google Scholar

- Research which is freely available for redistribution

Submit your manuscript at

www.biomedcentral.com/submit
C Biomed Central 